\title{
Effect of Inoculum Concentration and Interrupted Wetness Duration on the Development of Anthracnose Fruit Rot of Strawberry
}

Bruna B. Forcelini, University of Florida, Gulf Coast Research and Education Center, Wimauma 33598; Fabricio Packer Gonçalves, Dow AgroSciences, São Paulo, SP, Brazil; and Natalia A. Peres, University of Florida, Gulf Coast Research and Education Center

\begin{abstract}
Anthracnose fruit rot (AFR) of strawberry, caused by Colletotrichum acutatum, greatly affects production if not controlled. Application of fungicides in addition to the use of less susceptible cultivars are important tools for AFR control. The effects of interrupted wetness duration and inoculum concentration on the development of AFR were evaluated on strawberry cultivars with different levels of susceptibility. Fruit rot and flower blight incidence generally increased with increasing inoculum

concentration. 'Camarosa' and 'Treasure' were more susceptible than 'Strawberry Festival' and flowers were more susceptible than immature fruit for most cultivars. Interruption in wetness periods had a significant effect on disease incidence when fruit where exposed to dry periods of $6 \mathrm{~h}$ or more compared with $24 \mathrm{~h}$ of continuous wetness. The results of this study will be used to refine a disease-warning system to predict AFR outbreaks in Florida strawberry production fields.
\end{abstract}

Florida is the leading U.S. producer of fresh strawberry (Fragaria $x$ ananassa) during winter months (USDA-NASS 2013). Although a perennial, strawberry plants are cultivated in annual cropping systems in Florida (Brown 2003; Strand 2008). Anthracnose fruit rot (AFR), caused by Colletotrichum acutatum J. H. Simmonds, can cause losses greater than $70 \%$ in commercial production fields planted with susceptible strawberry cultivars (Legard et al. 2003; Mertely and Peres 2012). In Florida, $C$. acutatum inoculum does not oversummer in the soil and on plant debris; thus, annual reintroduction of the pathogen on transplants harboring quiescent infections represents the principal source of primary inoculum from which epidemics develop (Howard et al. 1992; Maas 1998). Conidia are produced from quiescent infections on transplant foliage (Leandro et al. 2003b; Maas 1998; Mertely and Peres 2012) and are then disseminated to flowers and fruit by splashing water (Leandro et al. 2003b; Mertely and Peres 2012; Strand 2008). The most characteristic anthracnose symptoms on strawberry are flower blight and fruit rot (Maas 1998; Peres et al. 2005) but the pathogen can also affect leaves, petioles, stolons, crowns, and roots.

AFR development is significantly affected by environmental factors (Peres et al. 2005; Strand 2008). Temperatures ranging from 15 to $30^{\circ} \mathrm{C}$ are favorable for anthracnose development (Strand 2008), with the optimal temperature being approximately $25^{\circ} \mathrm{C}$ (Wilson et al. 1990). However, the effect of temperature on anthracnose development is greatly dependent on its interaction with leaf wetness duration (WD) (Wilson et al. 1990). Leaf wetness periods of $4 \mathrm{~h}$ or more are required for conidial germination at temperatures of 21 to $33^{\circ} \mathrm{C}$ (Leandro et al. 2003a). In Florida, interruptions of wetness periods are frequent but how these interruptions affect $C$. acutatum infection is not known.

Weather conditions during plant establishment in Florida rarely limit establishment of the disease. Temperatures range from 20 to $30^{\circ} \mathrm{C}$ and up to $8 \mathrm{~h}$ of overhead irrigation are provided for 7 to 10 days after planting. In practice, timing and severity of initial symptom development on strawberry plants depend primarily upon the quantity of inoculum produced from quiescent infections and the susceptibility of the cultivar. If transplants are already infected, suppressing the disease and the subsequent dispersal of inoculum becomes difficult, because Florida growers may plant cultivars exhibiting a broad range of susceptibility to AFR in close proximity. Thus, even moderately

Corresponding author: N. A. Peres; E-mail: nperes@ufl.edu

Accepted for publication 30 October 2016.

() 2017 The American Phytopathological Society resistant cultivars are at risk when grown in proximity to large areas with sources of inoculum from susceptible cultivars.

Management of AFR depends primarily on judicious use of fungicides and complementary cultural practices. An ideal approach to manage AFR would be to avoid introduction of the pathogen into commercial fields by planting anthracnose-free transplants. At present, this is impractical, because plants with quiescent infections may not show symptoms at planting (Mertely and Peres 2012). Given Florida's AFR-favorable weather at the time of plant establishment, growers plant less-susceptible cultivars to mitigate disease outbreaks and reduce inoculum dissemination (Chandler et al. 2006). However, fruit quality and yield remain the principal criteria by which Florida growers select cultivars and, thus, blocks of interspersed resistant and susceptible cultivars are common for reasons unrelated to disease management.

Chemical suppression of AFR in Florida involves frequent, often weekly, fungicide applications (Mertely and Peres 2012; Turechek et al. 2006). Applications of broad-spectrum, multisite protectant fungicides such as captan at minimal labeled rates start early (November and December) in the season (Mertely and Peres 2012). Fungicide application rates are increased between January and March as temperature and leaf wetness approach the optimum for AFR development and inoculum has increased. Once disease is detected in the field, single-site fungicides such as azoxystrobin and pyraclostrobin that inhibit fungal respiration are recommended in combination with multisite fungicides (Daugovish et al. 2009; Mertely and Peres 2012).

Unacceptable levels of AFR can develop despite programmatic and regular use of fungicides. Timing of fungicide applications is extremely important to their efficacy. Different thresholds of a model (based on temperature and leaf wetness) used to time and reduce the number of fungicide applications for AFR control were evaluated (MacKenzie and Peres 2012). Results provided the basis for development of a web-based advisory system named the Strawberry Advisory System (StAS; http://agroclimate.org/tools/strawberry) (Pavan et al. 2011). At present, StAS does not take into account plant organ, cultivar susceptibility, or the initial inoculum concentration of $C$. acutatum on strawberry transplants at establishment. Initial $C$. acutatum contamination levels can vary greatly and refining the output of the StAS based upon this factor may reduce the number of fungicide applications even further because the system is conservative and currently assumes that $C$. acutatum inoculum is present. Also, the StAS requires an interruption of at least $4 \mathrm{~h}$ between wetness periods before a new wetness period. If the dry gap is less than $4 \mathrm{~h}$, it is considered a continuous wetness period and leaf wetness hours accumulate. However, this rule was implemented based on studies of infection models for different pathosystems such as Botrytis cinerea on grape and strawberry (Broome et al. 1995; Bulger et al. 1987). Refining the 
StAS output based upon the broad range of cultivar susceptibility to AFR and plant phenology may result in additional savings in fungicide use under suboptimum conditions, without additional risk of disease losses. In addition, validating whether the current 4-h dry gap used in the StAS is adequate for C. acutatum may help in predicting AFR outbreaks and timing fungicide applications. Therefore, the objectives of this study were to evaluate the effects of interrupted WD and inoculum concentration on the development of AFR on flowers and immature fruit of cultivars with different susceptibility levels under field and laboratory conditions.

\section{Materials and Methods}

Fungal isolates and culture. Four isolates of C. acutatum (98-324, $2-163,2-179$, and 3-32) were used for plant inoculation. Isolates 2-163, 2-179 and 3-32 were sequenced (G3PD, GS, and ITS regions) in a previous study (MacKenzie et al. 2009). Isolates from strawberry petiole (2-163), fruit (98-324 and 2-179), and crown (3-32) were maintained on filter paper in a sterile envelope in an airtight container with Drierite (W. A. Hammond Drierite Company, Ltd.) at $-4^{\circ} \mathrm{C}$. To revive the isolates, a small piece of filter paper (approximately $4 \mathrm{~mm}^{2}$ ) containing the isolate was placed on a $90-\mathrm{mm}$-diameter plate with potato dextrose agar and grown for 8 days at $22^{\circ} \mathrm{C}$.

Effect of inoculum concentration on AFR development. To determine the effect of different inoculum concentrations on the development of AFR on different strawberry cultivars, field experiments were conducted during the 2011-12 Florida strawberry season, whereas laboratory detached-fruit experiments were performed using fruit harvested during the 2012-13 season.

Field trials. Bare-root transplants of 'Camarosa', 'Treasure', and 'Strawberry Festival' strawberry were established in mid-October 2011 at the University of Florida Gulf Coast Research and Education Center in Wimauma. Prior to transplant, plastic mulch-covered beds were fumigated with 1,3-dichloropropene and chloropicrin (Telone C-35; Dow AgroSciences). Beds were $91.4 \mathrm{~m}$ long, $71 \mathrm{~cm}$ wide, $15 \mathrm{~cm}$ high at the edges, and $18 \mathrm{~cm}$ high at the center. The distance between the centers of the beds was $1.2 \mathrm{~m}$ and transplants were placed $30 \mathrm{~cm}$ apart in two rows. For plant establishment, transplants were overhead irrigated from 8 to $10 \mathrm{~h} /$ day for 10 to 12 days and then irrigated and fertilized daily through drip irrigation for the rest of the season.

Four inoculum concentrations $\left(10^{3}, 10^{4}, 10^{5}\right.$, and $10^{6}$ conidia/ml $)$ of C. acutatum and a control (deionized water) were tested. Isolates $98-$ $324,2-179$, and 3-32 were revived as previously described and grown for 8 days until fungal mycelium covered two-thirds of the plate. Colonies were scraped using a glass rod and sterile water to obtain conidial suspensions. The conidial suspensions were filtered through a double layer of cheesecloth and counted with a hemocytometer (Bright-Line; Hausser Scientific), then adjusted to each concentration.

In all, 50 strawberry plants were chosen arbitrarily and flagged (10 plants per treatment in five treatments). No AFR symptoms were observed prior to inoculation. On the days of inoculation (21 January and 14 February 2012), plant organs were tagged with different tape colors to identify the stages to be inoculated. To standardize the time of inoculation, flowers had to be open, have intact petals, and fresh yellow pollen; immature fruit had chlorophyll and were not starting to turn white; pink fruit had lost chlorophyll and started to turn pink; and mature fruit were beginning to turn or were already red. Tagged plant organs were mist sprayed with about $250 \mu$ l of the conidial suspensions at the designated concentration with an atomizer (Spra-tool; Crown). Immediately after inoculation, plants were covered with plastic bags ( 46 by $61 \mathrm{~cm}$ ) with a small amount of deionized water to maintain humidity. Sixteen hours after inoculation, plastic bags were removed and plants were allowed to dry. Mean temperature during the inoculation period (time of inoculation until bags were removed) was $13^{\circ} \mathrm{C}$ (12 January) and $16^{\circ} \mathrm{C}$ (14 February). Disease incidence was evaluated as the percentage of tagged fruit or flowers exhibiting anthracnose lesions. Tagged plant organs were evaluated for 10 days, starting 5 days after inoculation. Treatments were completely randomized and the experiment was conducted twice.

Trials with detached fruit. Five inoculum concentrations $\left(10^{2}\right.$, $10^{3}, 10^{4}, 10^{5}$, and $10^{6}$ conidia/ml) of the mixture of $C$. acutatum isolates 98-324, 2-179, and 3-32 plus a control (deionized water) were tested in the detached-fruit trial. Immature fruit of 'Camarosa' and 'Strawberry Festival' that averaged 2 to $3 \mathrm{~cm}$ in diameter and had receptacles with chlorophyll were harvested from the field and selected for uniformity. Fruit were surface disinfested using $0.7 \%$ sodium hypochlorite for $6 \mathrm{~min}$, rinsed four times with sterile water, and placed in egg cartons inside plastic boxes. Four replications of four immature fruit per concentration-cultivar combination were arranged in a randomized complete block design and were surface dried for 20 min in a laminar flow hood. To maintain humidity in the boxes, $75 \mathrm{ml}$ of deionized water was placed under the egg cartons. Inoculum was prepared as described for the field experiment. The upper part of each fruit was inoculated with a $5-\mu l$ droplet of the conidial suspension. Plastic boxes were covered and maintained at room temperature $\left(23 \pm 1^{\circ} \mathrm{C}\right)$ for 9 days. Fruit were evaluated for disease incidence starting 5 days after inoculation. The experiment was repeated once.

Influence of interrupted wetness periods on AFR development. Trials were conducted during the 2013-14 and 2014-15 strawberry seasons. In each season, 250 bare-root transplants of 'Strawberry Festival' were planted in plastic pots $(15 \times 15 \times 16 \mathrm{~cm})$ filled with potting mix containing Canadian sphagnum peat $(65 \%)$, perlite, and vermiculite (Fafard204). Plants were fertilized and irrigated daily and remained in a greenhouse until they were ready for inoculation.

A suspension of $10^{6}$ conidia/ml of the isolates 2-163, 2-179, and 3-32 was prepared as described above on the day of inoculation. Immature fruit were tagged according to the treatment (Table 1) and inoculated with approximately $150 \mu \mathrm{l}$ of the conidial suspension or sterile water (control) using an atomizer. After inoculation, plants were placed inside plastic bags and subjected to continuous or interrupted wetness periods at $25^{\circ} \mathrm{C}$ in the dark. The continuous wetness period consisted of $24 \mathrm{~h}$ of wetness. For the interrupted wetness, plants had initial wetness periods of 8 or $12 \mathrm{~h}$, followed by a dry period of $0,2,4,6$, and $8 \mathrm{~h}$ (only for the 12-h treatment). After the dry period, inoculated fruit were sprayed with $150 \mu \mathrm{l}$ of water, bagged, and kept at $25^{\circ} \mathrm{C}$ for an additional 16 or $12 \mathrm{~h}$ to complete a 24-h period (Table 1). Plants were removed from bags $30 \mathrm{~min}$ before the end of the initial and final wetness periods and were dried with a fan. Inoculated plants were incubated at $25^{\circ} \mathrm{C}$ with a photoperiod of $12 \mathrm{~h}$ of light and $12 \mathrm{~h}$ of darkness for 9 days. Disease incidence on tagged fruit was evaluated 9 days after inoculation. The number of immature fruit per treatment varied according to availability at the time of the experiment and was $10,8,22$, and 15 from the first to fourth trial. The experiments were arranged in a completely randomized design and were conducted four times.

Statistical analysis. Incidence values were arcsine transformed and both disease incidence and arcsine-transformed values were used for the statistical analysis. An analysis of variance was conducted to test the effects of experiment, inoculum concentration, WD, cultivar, plant organ, and their interactions (SAS, version 9.4; SAS Institute). Data from homogenous trials for each cultivar were combined and used to analyze treatment effects and plant organ susceptibility using the least significant difference. The relationship between field and

Table 1. Continuous and interrupted wetness period treatments to assess infection of strawberry by Colletotrichum acutatum

\begin{tabular}{lcc}
\hline & Treatment (h) & \\
\hline Wet & Dry & Wet \\
\hline 24 inoculated & - & - \\
24 control & - & - \\
8 & - & - \\
8 & 2 & 16 \\
8 & 4 & 16 \\
8 & 6 & 16 \\
12 & - & - \\
12 & 2 & 12 \\
12 & 4 & 12 \\
12 & 6 & 12 \\
12 & 8 & 12 \\
\hline
\end{tabular}


detached-fruit trials in the inoculum concentration assay was analyzed using a correlation analysis (SAS).

\section{Results}

Effect of inoculum concentration on AFR development. Field trials. The effects of strawberry cultivar $(P=0.0013)$ and inoculum concentration $(P<0.0001)$ were significant. Disease incidence increased with increasing inoculum concentration from 0 to $10^{6}$ conidia/ml for 'Strawberry Festival', 'Treasure', and 'Camarosa'. Plant organ effect was significant for the more susceptible 'Camarosa' $(P=0.0011)$ and 'Treasure' $(P=0.0179)$, and strawberry flowers had higher disease incidence than immature fruit. For the moderately susceptible 'Strawberry Festival', disease incidence on flowers and immature fruit did not differ $(P=0.2090)$. When data from strawberry organs were analyzed separately, disease incidence of flowers and immature fruit did not differ between the highly susceptible 'Camarosa' and 'Treasure' but incidence was higher than for 'Strawberry Festival'.

A second-order polynomial regression indicated that disease incidence on immature fruit and flowers of the three cultivars increased with an increase in inoculum concentration from 0 to $10^{6}$ conidia $/ \mathrm{ml}$ and the lowest inoculum concentration required for disease development differed among plant organs for 'Strawberry Festival' (Fig. 1). AFR symptoms appeared first on flowers of 'Strawberry Festival' inoculated with $10^{3}$ conidia/ml, whereas a higher inoculum concentration $\left(10^{4}\right.$ conidia/ml $)$ was needed for immature fruit. For the highly susceptible cultivar (Camarosa), AFR symptoms were observed first on flowers inoculated with $10^{3}$ conidia/ml. However, immature fruit of 'Treasure' and 'Camarosa' and flowers of 'Treasure' had low levels of AFR even on the control treatment (Fig. 1). Disease incidence on 'Camarosa' and 'Strawberry Festival' flowers was higher than on immature fruit at all inoculum concentrations. Similar results were observed for 'Treasure'; however, at $10^{3}$ conidia $/ \mathrm{ml}$, disease incidence was higher on immature fruit than on flowers. At the highest concentration $\left(10^{6}\right.$ conidia/ml $)$, disease incidence on flowers reached $46 \%$ ('Strawberry Festival'), 78\% ('Camarosa'), and 80\% ('Treasure') whereas, on immature fruit, maximum disease incidence of 'Strawberry Festival', 'Camarosa', and 'Treasure' was 31, 52, and 43\%, respectively.

AFR incubation period was shorter for flowers than for immature fruit for all three cultivars (Fig. 2). However, 'Strawberry Festival' had a longer incubation period than 'Treasure' or 'Camarosa' for both plant organs. For 'Treasure', the incubation periods on immature fruit and flowers were 5.75 and 5.25 days, respectively, whereas, for 'Strawberry Festival', the incubation period was 8 days for immature fruit and 7.25 days for flowers.

Detached-fruit trial. As in field trials, disease incidence increased with increasing inoculum concentration on detached fruit (Fig. 3). The minimum concentration of conidia required for AFR development was $10^{3}$ conidia/ml for 'Camarosa', whereas 'Strawberry Festival' required $10^{4}$ conidia/ml. Disease incidence was significantly higher on 'Camarosa' than on 'Strawberry Festival' at all inoculum concentrations. The highest disease incidence was observed at the highest inoculum concentration $\left(10^{6}\right.$ conidia/ml) for both 'Camarosa' (78\%) and 'Strawberry Festival' (50\%).

Correlation between detached-fruit and field trials. Analysis of correlation indicated that field and detached-fruit trials were significantly
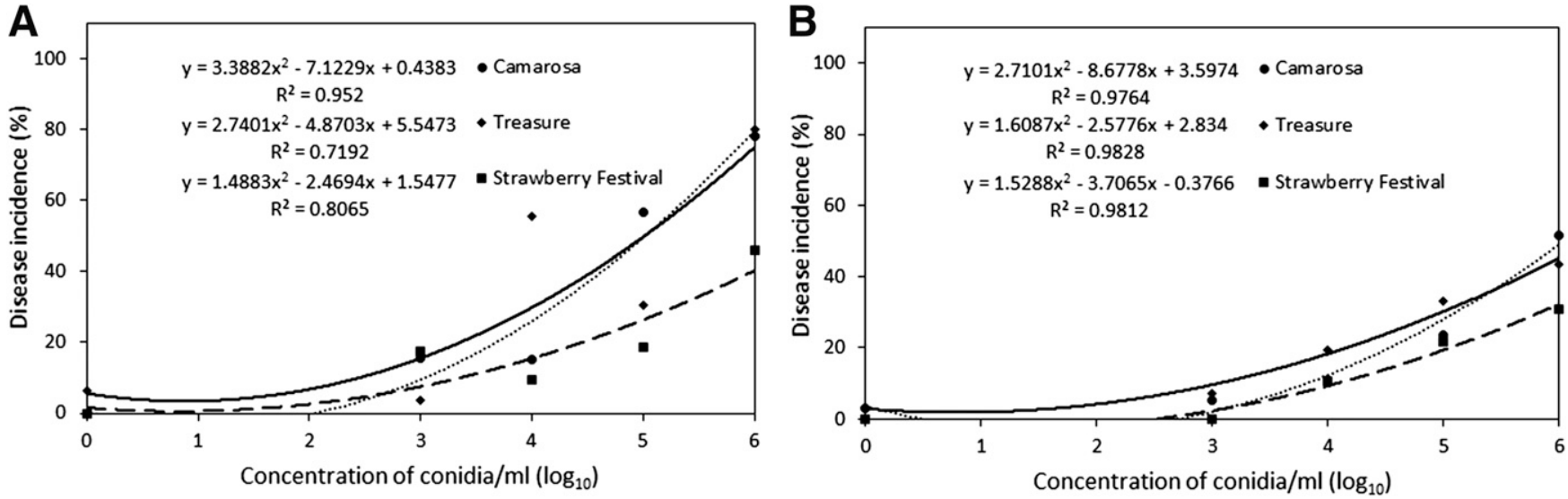

Fig. 1. Regression of inoculum concentration of Colletotrichum acutatum on anthracnose fruit rot development on different plant organs of three strawberry cultivars. A, Inoculated flowers. B, Inoculated immature fruit. Data are the means of two field trials for 'Strawberry Festival', 'Treasure', and 'Camarosa'.

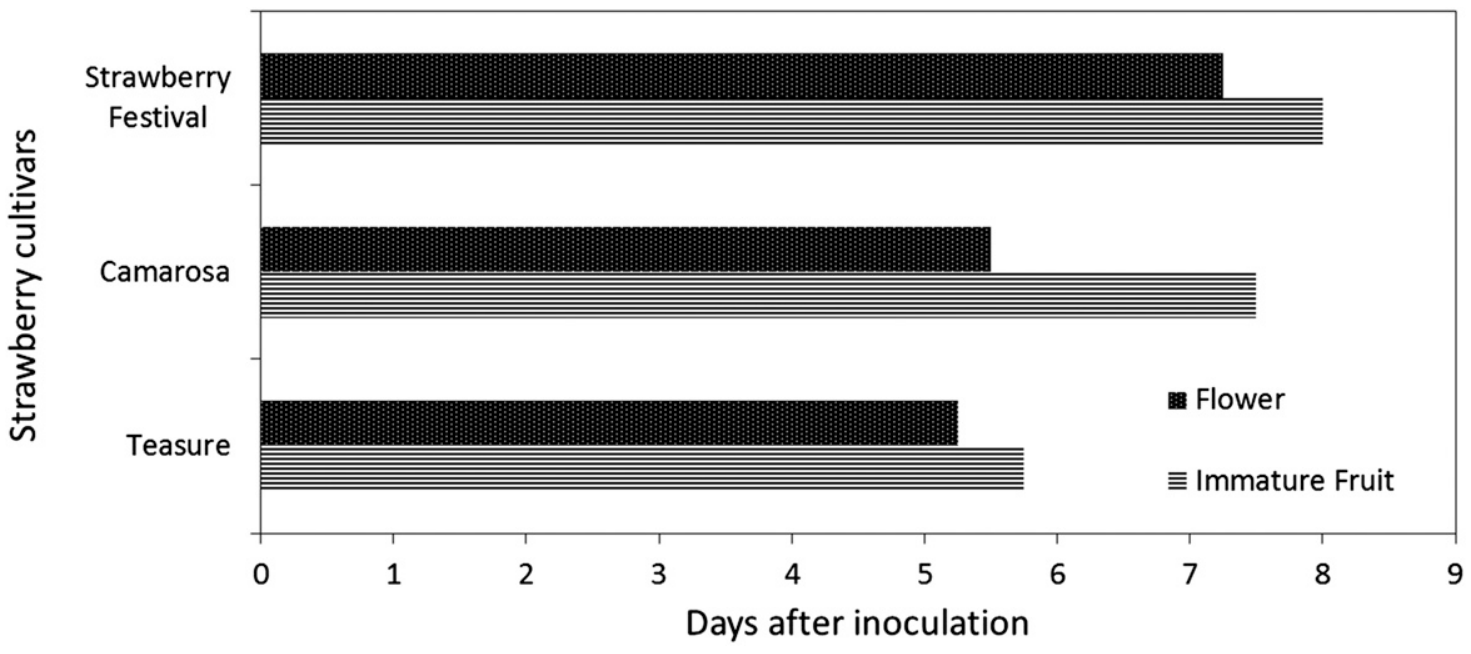

Fig. 2. Incubation period for immature fruit and flowers of different strawberry cultivars inoculated with Colletotrichum acutatum at $10^{6}$ conidia/ml in a field trial. 
correlated for each of the strawberry cultivars with an $r^{2}$ of 0.94 (Strawberry Festival) and 0.90 (Camarosa).

Influence of interrupted wetness periods on AFR development. The highest disease incidence was observed when plants were exposed to $24 \mathrm{~h}$ of continuous wetness. Wetness periods interrupted for $6 \mathrm{~h}$ reduced fruit disease incidence when compared with $24 \mathrm{~h}$ of continuous wetness. However, disease incidence was not different from treatments that had a 2- or 4-h dry period after initial wetness of 8 or $12 \mathrm{~h}$. When wetness interruption was greater than $6 \mathrm{~h}$, a minimal decrease in disease incidence from 62 to $61 \%$ was observed for the treatment with $12 \mathrm{~h}$ of initial wetness (Fig. 4).

When comparing continuous wetness periods, infection levels of plants exposed to an 8- or 12-h period were lower than those with a 24-h period. Disease incidence, however, was only significantly different between the 8- and 24-h treatments. Initial WD of $12 \mathrm{~h}$ followed by different dry periods resulted in significantly higher $(P=$ 0.0145 ) disease incidence than treatments with $8 \mathrm{~h}$ of initial wetness. The effect of dry period length was more notable when plants were exposed to $8 \mathrm{~h}$ compared with $12 \mathrm{~h}$ of initial wetness. That is, the increase in the length of dry periods resulted in a decrease in disease incidence.

\section{Discussion}

Development of AFR of strawberry is greatly affected by the concentration of inoculum and WD. AFR incidence generally increased with increasing inoculum concentration for all strawberry cultivars and plant organs in field and detached-fruit trials. The same was true for anthracnose of almond, where disease severity increased nonlinearly with increasing inoculum concentration (Diéguez-Uribeondo et al. 2011). Our results showed symptoms on flowers at a low inoculum concentration $\left(10^{3}\right.$ conidia/ml) for the highly (Camarosa) and moderately (Strawberry Festival) susceptible cultivars. Similar results were observed for $C$. acutatum on almond cultivars with different levels of susceptibility (Diéguez-Uribeondo et al. 2011). On the other hand, a higher inoculum concentration $\left(10^{4}\right.$ conidia/ml $)$ was required for AFR development on immature fruit of 'Strawberry Festival', compared with highly susceptible 'Camarosa' and 'Treasure'. Disease incidence on immature fruit of the highly susceptible cultivars was significantly higher than for the moderately susceptible at all inoculum concentrations. Similar results were also observed when detached immature fruit of 'Camarosa' and 'Strawberry Festival' were inoculated with different concentrations of $C$. acutatum conidia. Not only was disease incidence higher for 'Camarosa' when compared with 'Strawberry Festival' at all inoculum concentrations but also the minimum concentration required for AFR development was lower for 'Camarosa' $\left(10^{4}\right.$ conidia/ml $)$ than for 'Strawberry Festival' ( $10^{5}$ conidia/ml). Interestingly, the minimum inoculum concentration required for AFR symptom development was higher on detached fruit than in field trials for 'Strawberry Festival' and 'Camarosa'. This difference may be explained by inoculation methodology. In the field trials, the entire fruit was spray inoculated whereas, on the detached fruit, a small droplet was used to inoculate the surface.

In addition to cultivar susceptibility, plant organ is an important factor for AFR development. Strawberry flowers were more susceptible and had a shorter incubation period than immature fruit of the highly susceptible 'Camarosa' and 'Treasure'. In fact, higher susceptibility of strawberry flowers than immature fruit (Maas 1998) has already been observed in 'Camarosa' and 'Strawberry Festival' (J. Mertely, personal communication). Strawberry AFR incidence was also shown to increase from immature to red (mature) fruit (Wilson et al. 1990). Therefore, immature fruit are less susceptible to AFR than flowers or mature fruit. Because flowers have a shorter incubation period than immature fruit and, therefore, shorter disease cycles, inoculum builds up more rapidly for subsequent infection in strawberry fields. In addition, when planting highly susceptible cultivars such as Camarosa and Treasure, growers should use fungicides with protective and curative effects such as the quinone outside inhibitor fungicides azoxystrobin and pyraclostrobrin when flowers are predominant.

Strawberry transplants may arrive from nurseries already infected with $C$. acutatum. Quiescent infections may have been present without AFR symptoms at the beginning of the experiments but, when exposed to favorable weather conditions, flowers of 'Treasure', and immature fruit of 'Treasure' and 'Camarosa' showed AFR symptoms in the control treatment. For the less susceptible 'Strawberry Festival', no disease occurred in any of the control treatments and, therefore, disease symptoms observed on flowers and immature fruit were a result of inoculations during the experiment. Detection of quiescent infections and quantification of $C$. acutatum inoculum on transplants prior to planting can help growers and extension agents to adopt adequate disease management practices. Mertely and Legard (2004) developed a petiole-freeze method to detect $C$. acutatum on symptomless strawberry plants. This has been successful in detecting latent AFR infections; however, it takes 5 to 7 days to detect $C$. $a c u$ tatum acervuli and it is not quantitative. Recently, an inexpensive, highly specific, efficient assay, called the loop-mediated isothermal amplification (LAMP), has been developed to detect and quantify C. acutatum inoculum on symptomless plants (Notomi et al. 2000; Tomita et al. 2008; Zhang et al. 2016). The development of such molecular tools may allow detection of quiescent infections and

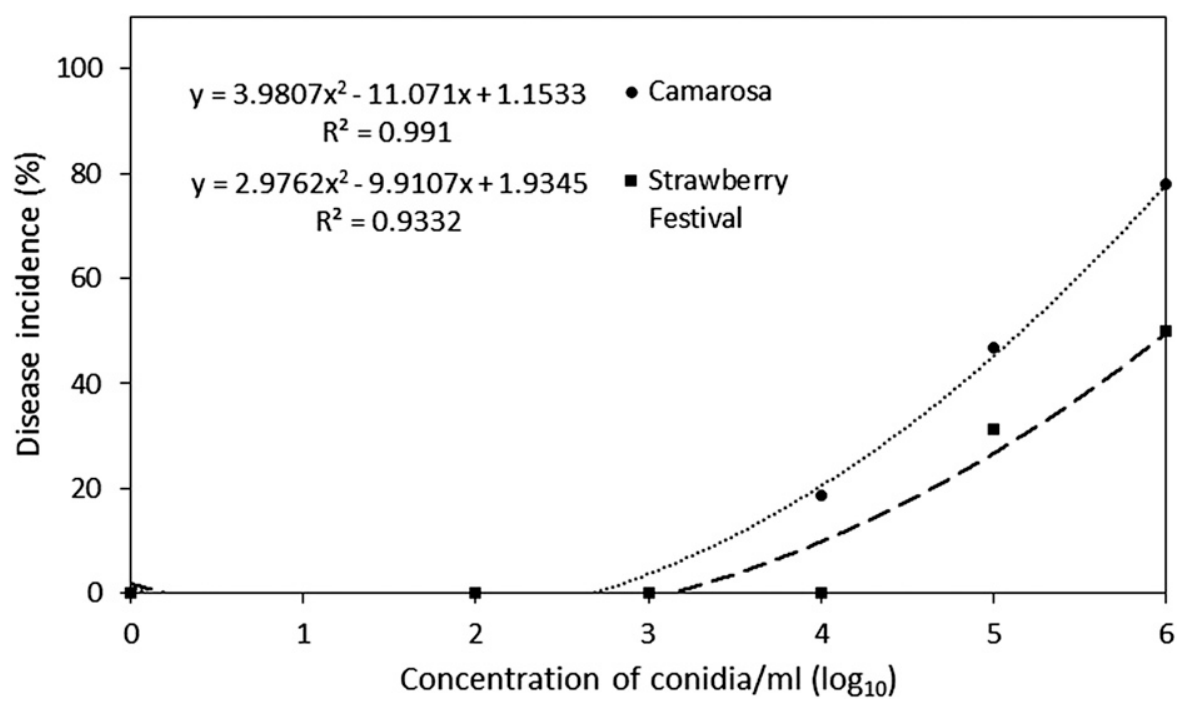

Fig. 3. Regression of inoculum concentration of Colletotrichum acutatum and anthracnose fruit rot development on detached immature strawberry fruit of cultivars. A, 'Camarosa' and B, 'Strawberry Festival'. Plants were inoculated with 0 to $10^{6} \mathrm{conidia} / \mathrm{ml}$ and maintained at continuous wetness and room temperature for 9 days. Data are the means of two trials. 
quantification of the amount of inoculum present on transplants so that initial spray applications can be recommended according to those results and the susceptibility of the strawberry cultivar.

The results with detached-fruit and field trials of 'Camarosa' and 'Strawberry Festival' were correlated and show that similar results can be generated under laboratory conditions using detached fruit. The detached-fruit assay is advantageous because environmental conditions in the laboratory can be controlled. However, detached fruit senesced and matured faster than attached fruit and, thus, symptoms developed faster. This may be because detached fruit were under ideal conditions $\left(23 \pm 1^{\circ} \mathrm{C}\right.$ and high humidity) in the laboratory, whereas fruit inoculated in the field were exposed to fluctuating temperatures.

Interruption of wetness periods had a significant effect on C. acutatum infection on immature strawberry fruit. Exposure of $C$. acutatum conidia to dry periods was more detrimental to AFR infection when initial wetness periods were shorter than $12 \mathrm{~h}$. This may be because spore germination had already been initiated but infection was not complete. When plants were exposed to an initial $12 \mathrm{~h}$ of wetness, the different lengths of dry periods did not have a significant impact on disease incidence, indicating that the initial period of wetness was sufficient for spore germination and infection of fruit. Similarly, dry periods after an initial 12-h wetness period were less disruptive to Coccomyces hiemalis on sour cherry than dry periods after 4 and $8 \mathrm{~h}$ of wetness (Eisensmith et al. 1982). The influence of dry periods for C. acutatum infection on strawberry fruit is of practical importance for the StAS developed in Florida that monitors weather conditions favorable for AFR development. The system currently considers a dry period of at least $4 \mathrm{~h}$ for a new wetness event (Pavan et al. 2011). However, disease thresholds selected to trigger fungicide applications on the StAS were based on growth-chamber studies conducted under continuous wetness and the 4-h dry gap was implemented following studies in other pathosystems (Broome et al. 1995; Bulger et al. 1987; MacKenzie and Peres 2012; Wilson et al. 1990).

Studies used to develop the specific fungicide recommendations in the StAS were also based on studies simulating continuous short ( 6 or $8 \mathrm{~h}$ ) or long (18 or $24 \mathrm{~h}$ ) wetness events (Peres et al. 2010; Turechek et al. 2006). AFR control under short wetting periods was effective with captan applications made before or up to $8 \mathrm{~h}$ after inoculation, whereas pyraclostrobin and fludioxonil + cyprodinil effectively controlled the disease when applied up to $24 \mathrm{~h}$ postinoculation. Under the long wetting periods, however, only pyraclostrobin and fludioxonil + cyprodinil were effective in controlling AFR postinoculation. The ineffectiveness of captan after long wetting periods is likely because it only affects the spores that have not yet penetrated fruit tissue. Thus, an initial wetness period of $8 \mathrm{~h}$ is not sufficient to cause high levels of $C$. acutatum infection and the disease can still be controlled with captan applications.

In our studies, inoculum concentration influenced disease outcome depending on the cultivar susceptibility. In practical terms, it means that even low levels of quiescent infection of strawberry transplants can result in symptom development on highly susceptible cultivars. Plant organ susceptibility should be taken into account in the StAS
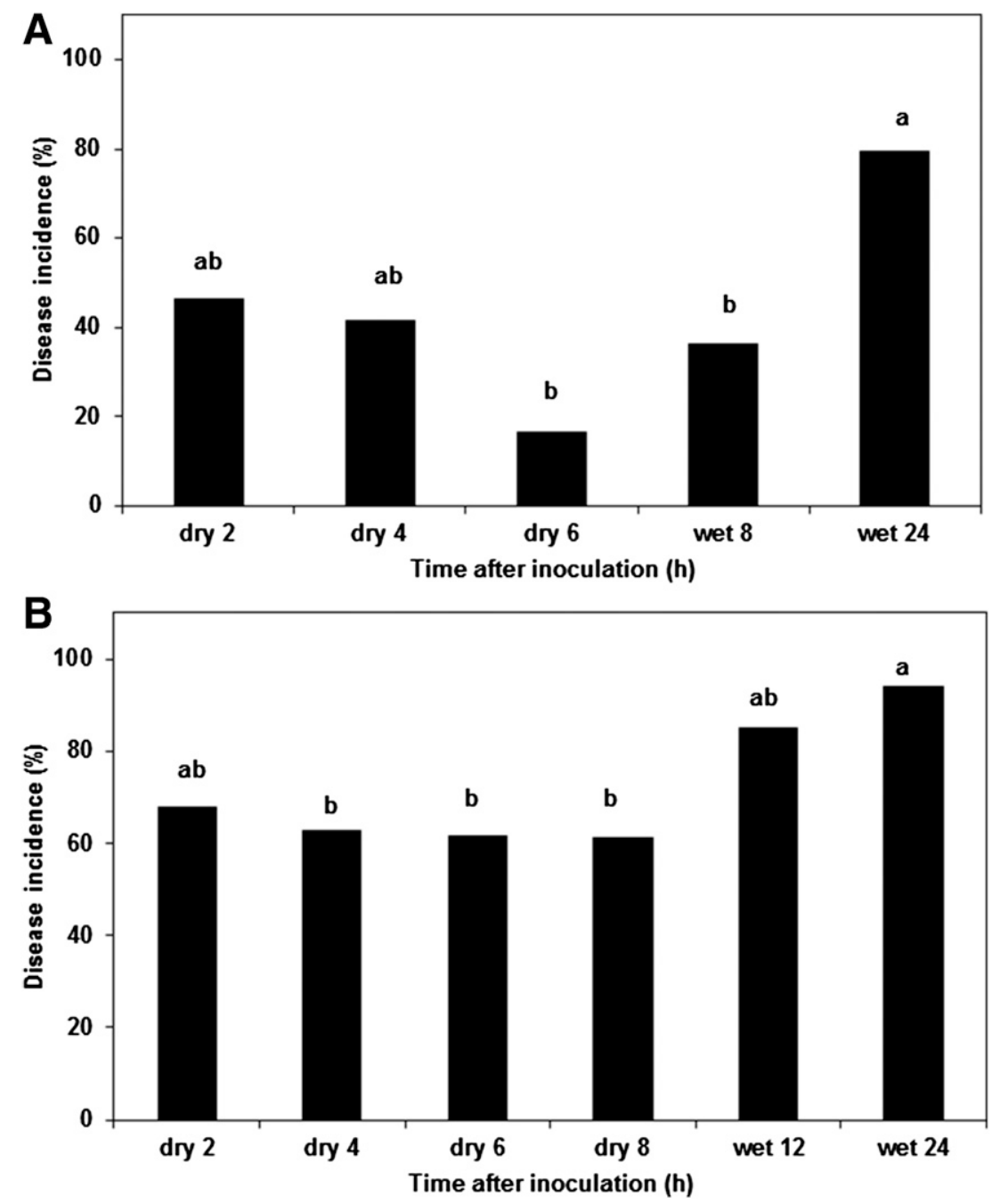

Fig. 4. Effects of interrupting A, an 8-h continuous wetness period with a 2-, 4-, and 6-h dry period; and B, a 12-h continuous wetness period with a 2-, 4-, 6-, and 8-h dry period on anthracnose fruit rot incidence on immature strawberry fruit. Combined data from two experiments. 
recommendations for AFR control. Because flowers are more susceptible than immature fruit of most cultivars, a more strict fungicide program should be recommended when flowers predominate. The differences in disease susceptibility are insufficient to permit flexibility in disease management; however, the use of less-susceptible cultivars may reduce risk in the case of a disease outbreak. Growers could take more risks when planting less-susceptible cultivars because disease is unlikely to become epidemic when following spray recommendations from the system. However, for highly susceptible cultivars, a quick assay to detect initial and quantitate quiescent infections, such as LAMP, would be beneficial. If high levels of inoculum are detected, a preventive spray schedule may be preferred for controlling AFR. Our results suggest that the dry period implemented in the StAS could potentially be increased to $6 \mathrm{~h}$ when plants have been exposed to a short wetness period of $8 \mathrm{~h}$ and to optimal temperature (approximately $25^{\circ} \mathrm{C}$ ). However, it might be logistically difficult to implement different dry periods for short and long wetness and $4 \mathrm{~h}$ may be a good and conservative estimate.

\section{Acknowledgments}

This research was funded by the United States Department of Agriculture National Institute of Food and Agriculture Project 2010-51181-211113. We thank R. Martin, L. Cordova, R. Roehrig, and E. Zuchelli for technical assistance.

\section{Literature Cited}

Broome, J. C., English, J. T., Marois, J. J., Latorre, B. A., and Aviles, J. C. 1995. Development of an infection model for Botrytis bunch rot of grape based on wetness duration and temperature. Phytopathology 85:97-102.

Brown, M. 2003. Florida strawberry production and marketing. Pages 31-42 in: The Strawberry: A Book for Growers, Others. N. F. Childers, ed. Dr. Norman N. Childers Publications, Gainesville, FL.

Bulger, M. A., Ellis, M. A., and Madden, L. V. 1987. Influence of temperature and wetness duration on infection of strawberry flowers by Botrytis cinerea and disease incidence of fruit originating from infected flowers. Phytopathology 77:1225-1230.

Chandler, C. K., Mertely, J. C., and Peres, N. A. 2006. Resistance of selected strawberry cultivars to anthracnose fruit rot and Botrytis fruit rot. Acta Hortic. 708:123-126.

Daugovish, O., Su, H., and Gubler, W. D. 2009. Preplant fungicide dips of strawberry transplants to control anthracnose caused by Colletotrichum acutatum in California. HortTechnology 19:317-323.

Diéguez-Uribeondo, J., Föster, H., and Adaskaveg, J. E. 2011. Effect of wetness duration and temperature on the development of anthracnose on selected almond tissues and comparison of cultivar susceptibility. Phytopathology 101:1013-1020.

Eisensmith, S. P., Jones, A. L., and Cress, C. E. 1982. Effects of interrupted wet periods on infection of sour cherry by Coccomyces hiemalis. Phytopathology 72:680-682.

Howard, M. H., Maas, J. L., Chandler, C. K., and Albregts, E. E. 1992. Anthracnose of strawberry caused by the Colletotrichum complex in Florida. Plant Dis. 76:976-981.
Leandro, L. F. S., Gleason, M. L., Nutter, F. W., Jr., Wegulo, S. N., and Dixon, P. M. 2003a. Influence of temperature and wetness duration on conidia and appressoria of Colletotrichum acutatum on symptomless strawberry leaves. Phytopathology 93:513-520.

Leandro, L. F. S., Gleason, M. L., Nutter, F. W., Jr., Wegulo, S. N., and Dixon, P. M. 2003b. Strawberry plant extracts stimulate secondary conidiation by Colletotrichum acutatum on symptomless leaves. Phytopathology 93: 1285-1291.

Legard, D. E., MacKenzie, S. J., Mertely, J. C., and Chandler, C. K. 2003. Evaluation of fungicides to control anthracnose fruit rot of strawberry, 20012002. Online publication. Fungic. Nematicide Tests 58:SMF009.

Maas, J. L., ed. 1998. Compendium of Strawberry Diseases. American Phytopathological Society, St. Paul, MN.

MacKenzie, S. J., and Peres, N. A. 2012. Use of leaf wetness duration and temperature to time fungicide applications to control anthracnose fruit rot of strawberry in Florida. Plant Dis. 96:522-528.

MacKenzie, S. J., Peres, N. A., Barquero, M. P., Arauz, L. F., and Timmer, L. W. 2009. Host range and genetic relatedness of Colletotrichum acutatum isolates from fruit crops and leatherleaf fern in Florida. Phytopathology 99:620-631.

Mertely, J. C., and Legard, D. E. 2004. Detection, isolation, and pathogenicity of Colletotrichum spp. from strawberry petioles. Plant Dis. 88:407-412.

Mertely, J. C., and Peres, N. A. 2012. Anthracnose Fruit Rot of Strawberry. Publ. No. PP-207. University of Florida, IFAS, EDIS, Gainesville.

Notomi, T., Okayama, H., Masubuchi, H., Yonekawa, T., Watanabe, K., Amino, N., and Hase, T. 2000. Loop-mediated isothermal amplification of DNA. Nucleic Acids Res. 28:e63.

Pavan, W., Fraisse, C. W., and Peres, N. A. 2011. Development of a web-based disease forecasting system for strawberries. Comput. Electron. Agric. 75: 169-175.

Peres, N. A., Seijo, T. E., and Turechek, W. W. 2010. Pre- and post-inoculation activity of a protectant and a systemic fungicide for control of anthracnose fruit rot of strawberry under different wetness durations. Crop Prot. 29: 1105-1110.

Peres, N. A., Timmer, L. W., Adaskaveg, J. E., and Correll, J. C. 2005. Lifestyles of Colletotrichum acutatum. Plant Dis. 89:784-796.

Strand, L. L. 2008. Integrated Pest Management for Strawberries, 2nd ed. University of California, Oakland.

Tomita, N., Mori, Y., Kanda, H., and Notomi, T. 2008. Loop-mediated isothermal amplification (LAMP) of gene sequences and simple visual detection of products. Nat. Protoc. 3:877-882.

Turechek, W. W., Peres, N. A., and Werner, N. A. 2006. Pre- and post-infection activity of pyraclostrobin for control of anthracnose fruit rot of strawberry caused by Colletotrichum acutatum. Plant Dis. 90:862-868.

USDA-NASS. 2013. Economics, Statistics and Market Information System. U.S. Strawberry Industry. Online publication. United States Department of Agriculture-National Agricultural Statistics Service. http://usda.mannlib.cornell. edu/MannUsda/viewDocumentInfo.do?documentID=1381

Wilson, L. L., Madden, L. V., and Ellis, M. A. 1990. Influence of temperature and wetness duration on infection of immature and mature strawberry fruit by Colletotrichum acutatum. Phytopathology 80:111-116.

Zhang, X. Harrington, T. C., Batzer J. C., Kubota, R., Peres, N. A, and Gleason, M. L. 2016. Detection of Colletotrichum acutatum sensu lato on strawberry by loop-mediated isothermal amplification. Plant Dis. 100:1804-1812. 